Lengua y Sociedad en el Mundo Hispánico

Language and Society in the Hispanic World

Editado por / Edited by

Julio Calvo Pérez (Universitat de València)

Luis Fernando Lara (E1 Colegio de México) Matthias Perl (Universität Mainz)

Armin Schwegler (University of California, Irvine)

Klaus Zimmermann (Universität Bremen)
Yolanda Congosto Martín

Elena Méndez García de Paredes (eds.)

\section{Variación linguiística y contacto de lenguas en el mundo hispánico}

In memoriam MANUEl Alvar

Vol. 27 


\title{
ESTRATEGIAS DISCURSIVAS DEL MENSAJE EMPRESARIAL: EL COMUNICADO DE PRENSA
}

\author{
ELENA LEAL ABAD \\ Universidad de Sevilla
}

\section{Introducción}

La intertextualidad constituye uno de los aspectos que el lingüista debe tener en cuenta en el estudio de los fenómenos relacionados con la variación. Y ello es así porque la construcción de un determinado texto no surge ex novo sino que viene dada por la tradición cultural en la que se inserta, hecho que condiciona no sólo su estructura sino también sus rasgos lingüísticos. Es lo que se conoce como modelos de textualidad o tradiciones discursivas ${ }^{1}$. El análisis textual se ha aplicado a numerosas tipologías dando como resultado una extensa bibliografia e importantes resultados tanto en diacronía como en sincronía. No obstante, algunas clases de textos, especialmente en el área de la comunicación, han sido desatendidas. Es verdad que en este campo de la información se ha abordado el estudio estructural de noticias, columnas, artículos, entrevistas (Méndez García de Paredes 2003), etc. pero queda por analizar un tipo de texto, propio del ámbito empresarial, a camino entre la información y la publicidad, que se produce con una frecuencia cada vez mayor en la sociedad actual. Se trata de los "comunicados de prensa", que pueden definirse como escritos dirigidos a los medios de comunicación en los que se informa de algún hecho relacionado con la empresa que se considera noticia o, al menos, se anuncia como tal. El objetivo último de estos textos es intentar captar espacio informativo (de ahí la necesidad de conocer

1. En este sentido, Oesterreicher (1997: 86) afirma lo siguiente: "El discurso [...] no sólo es manifestación o actualización de la actividad del hablar mediante reglas y normas de una lengua, sino que al mismo tiempo — y este punto se olvida muy a menudo - es siempre realización de modelos textuales, de modelos discursivos, o, en la terminología aquí adoptada, de tradiciones discursivas. Pero no hay que identificar las tradiciones discursivas exclusivamente con géneros o estilos literarios, ya que estas representan también formas de la interacción verbal cotidiana". 
las técnicas y rutinas de los medios) $)^{2}$ para no sólo lograr una objetividad mayor a la que proporciona la actividad publicitaria sino también disminuir la inversión económica que esta conlleva.

El uso que se haga del lenguaje en la redacción de estos escritos queda condicionado, pues, a esta doble finalidad que determinará, entre otros aspectos, la adjetivación, el orden de palabra y la estructura textual en la que son configurados. Este trabajo analizará las características lingüísticas más frecuentes en este tipo de texto para lograr los fines que se proponen y, de este modo, desentrañar algunas de las estrategias del mensaje empresarial.

\section{El poder de la comunicación en la sociedad de la información. El mensaje como creador de imagen}

Uno de los aspectos que mejor caracteriza a la sociedad actual, al menos en el mundo desarrollado, es la importancia de la comunicación (Álvarez/Caballero 1997: 25). No en vano se ha dado en llamar a esta época la "Sociedad de la información". El ámbito empresarial ${ }^{3}$ es consciente del poder que esta tiene para crear una buena imagen (entendiendo este término como el conjunto de rasgos característicos de un determinado organismo que le da una identidad propia al tiempo que lo distingue de otras entidades) y sabe que la comunicación es un elemento determinante para el desarrollo de sus diferentes actividades; de ahí que constituya un aspecto básico en su planificación estratégica. El objetivo final es que esta identidad sea positiva para contar con una opinión pública favorable. Y es que el público, a través de los mensajes que la empresa proyecta al exterior y que que-

2. Por eso normalmente esta labor la ejerce un periodista no porque el trabajo que desarrolle en el gabinete de prensa tenga carácter periodístico (a veces sí) sino más bien porque conoce la dinámica de funcionamiento de los medios de comunicación (horas de cierre, descenso de plantilla durante los fines de semana, características ideológicas y técnicas de los diferentes medios...). De este modo, es importante escoger cuidadosamente el día del envío para evitar que otros acontecimientos de mayor trascendencia informativa resten espacio informativo. En este punto, resulta frecuente plantearse si los profesionales de los gabinetes de comunicación están al servicio de la empresa o de la información.

3. Aunque normalmente se entiende empresa como una unidad de organización dedicada a actividades industriales, mercantiles o de prestación de servicios con fines lucrativos, en este trabajo el término adopta un sentido más abarcador, al hacer referencia a todo organismo que lleve a cabo alguna acción sobre su entorno, aunque esta no tenga fines lucrativos. De ahí que se incluya también otro tipo de instituciones como centros de investigación, fundaciones, departamentos de la administración pública, organismos oficiales, etc. 
dan retenidos en su memoria, va a ir configurando una imagen que condicionará su comportamiento.

Por eso, se ha observado en los últimos años un cambio en las estrategias de comunicación de las empresas: no sólo se transmite información, como sucedía antes, cuando esta tiene repercusión directa sobre la venta de los productos o servicios (sociedad industrial) sino que en la actualidad se exige una política informativa no exclusivamente publicitaria (sociedad de la información) ${ }^{4}$. Se ha pasado de una publicidad como técnica comercial a otra en la que los mensajes crean estereotipos o imágenes asociadas a determinadas marcas o instituciones. La publicidad en este caso se fundamenta más que en valores de carácter objetivo, en valores simbólicos asociados a determinados productos y, en última instancia, a la empresa que los origina (la marca Volvo, por ejemplo, se asocia a seguridad).

En este punto, cabe preguntarse por los cauces con los que cuenta una empresa para configurar y mantener su imagen social. En líneas generales, además de la comunicación interna que se establece con los diferentes elementos integrantes de la empresa, está la comunicación externa (esto es, la que se lleva a cabo con el entorno), en la cual pueden establecerse dos líneas de actuación: la actividad publicitaria y la labor llevada a cabo desde los Departamentos/Gabinetes de Comunicación o Prensa. Se trata de dos ámbitos profesionales bien diferenciados pero que se confunden a menudo. A continuación, se tratará de esbozar algunos rasgos generales de cada uno de ellos con el objetivo de distinguir los ámbitos de actuación y ver en qué medida los mensajes que originan pueden venir condicionados por estas características.

El Departamento de Publicidad se dirige a un público que es tratado y abordado como consumidor. El objetivo último es persuadirlo y convencerlo de los aspectos beneficiosos del producto o servicio que se le ofrece. Insertar un anuncio, a pesar de tener un alto coste económico, cuenta con la ventaja de que la empresa que se publicita puede controlar el momento de aparición y, con ello, seleccio-

4. Según Álvarez/Caballero (1997: 82), "Las organizaciones han dejado de relacionarse sólo con la sociedad a través de su producto material o ideológico. Al mensaje publicitario del producto han de unirse otras actuaciones, tales como el diálogo con el entorno. [...] Precisamente, ese enfoque ha hecho que progresivamente vaya diluyéndose la imagen de producto, servicio o marca dentro de la del productor; pierde valor lo que es comunicación del producto y la gana la comunicación institucional'. 
nar de algún modo al destinatario. El lenguaje empleado, de carácter persuasivo, vendrá condicionado no sólo por el receptor al que se dirige el producto sino por los objetivos comerciales, los canales a través de los que se difunde el mensaje, etc ${ }^{5}$. Se trata de (1) llamar la atención de los receptores para implicarlos (función fática) y (2) modificar su conducta (función apelativa), (3) hablar e informar de los productos (función referencial), exaltando y ponderando sus características (función expresiva) a través de (4) la estética del mensaje (función poética):

(1) "¿Te apetece un día redondo? Donuts".

(2) a. "iCambia de móvil por muy poco dinero!".

b. "No dejes pasar el momento Martín. Es ese momento que tú ya sabes...". c. "Planta joven. Viste como eres".

(3) a. "[Foto del juguete] Esto es un gran regalo. Didáctico, resistente y con un gran valor pedagógico [sonrisa de un niño]. Esto también. Con los juguetes Fisher-Price las sonrisas están garantizadas, por eso son regalos que no se olvidan. Fisher: Price. Regalos que no se olvidan".

b. "Alfa Romeo. La pasión de conducir".

(4) a. "La nueva batería Tudor Mágnum Plus es un plus en todos los sentidos: Plus en potencia. Con una mayor fuerza de arranque. Plus en durabilidad. Con más duración y menor autodescarga".

b. "Un poco de Magno es mucho".

El Departamento de Comunicación, por su parte, trata de cultivar su relación con los medios (prensa, radio, televisión y agencias de prensa). Estos gabinetes surgen porque las empresas son cada vez más conscientes de que su trabajo no puede prescindir de la labor llevada a cabo por estos medios y de la imagen que proyectan de ellas ${ }^{6}$. Existen muchos mecanismos para fortalecer la relación entre prensa y empresa: contacto directo o telefónico, entrevistas personales, organización de eventos, ruedas de prensa, etc. Pero sin duda, uno de los más efectivos y que constituye un instrumento de trabajo fundamental son los "comunicados de prensa", de los que se hablará en el siguiente apartado. El objetivo final de todos estos recursos es conquistar el mayor espacio informativo.

5. La relación con los medios de comunicación puede, no obstante, verse resentida o dañada por este tipo de acciones ya que, a excepción de empresas con un alto nivel de beneficios, que se publicitan en la mayoría, la elección supondría beneficiar a unos frente a otros. Asimismo, la ideología del medio podría connotar, marcar o relacionarse de algún modo con la de la entidad que en última instancia se publicita.

6. La presencia de las empresas en los medios no es importante exclusivamente si se hace una critica positiva de ellas sino que el simple hecho de que aparezca citada favorece su imagen. 
Como puede deducirse de lo dicho anteriormente, hay una clara diferencia entre la labor realizada por cada uno de estos departamentos. De una manera muy simplificada, podría resumirse en la distinción entre "vender" y "dar a conocer", es decir, entre acción persuasiva e informativa, hecho que condicionará el tipo de lenguaje empleado en uno u otro caso. No obstante, se hace necesario señalar que ambos departamentos están íntimamente relacionados y que, para un eficaz funcionamiento de la empresa, no puede prescindir uno del trabajo que el otro realj$\mathrm{za}^{\top}$. Asimismo, conviene señalar que el límite entre publicidad e información no es siempre nítido.

\section{La relación prensa-empresa: el comunicado como instrumento de comuni- cación}

Según se ha puesto de manifiesto, en la sociedad actual cada vez resulta más importante el papel que la imagen tiene para el desarrollo de las actividades llevadas a cabo por empresas, instituciones, organizaciones, etc. Uno de los medios más eficaces no sólo para crear sino también para mantener esa imagen es el lenguaje que estos organismos emplean en su comunicación externa, ya que a través de los mensajes que proyectan pueden lograr o fracasar en su intento de crear un clima de confianza. La labor desarrollada en este sentido por los gabinetes de prensa resulta fundamental. Estos departamentos cuentan entre sus instrumentos de trabajo con los comunicados de prensa. Se trata de escritos dirigidos a los medios de comunicación en los que se informa de algún hecho relacionado con la empresa que se considera noticia ${ }^{8} \mathrm{o}$, al menos, se anuncia como tal (el nombramiento de un nuevo cargo, una actividad, el balance de todo un año, la visita de alguna personalidad, etc.). El objetivo último es intentar captar espacio informativo para no sólo lograr una objetividad mayor a la que proporciona la actividad publicitaria sino también disminuir la inversión económica que esta conlleva ${ }^{9}$. El

7. Para Álvarez y Caballero (1997: 29) son tres "los rubros clásicos en los que hay que actuar para comunicar: la difusión de información a través de los medios de comunicación, la acción publicitaria y las relaciones públicas. Todos ellos están interconectados y una dirección global de comunicación debe abordar coordinadamente todos los ámbitos".

8. El problema es que los hechos que se emiten desde los gabinetes de comunicación suelen ser acontecimientos socialmente constructivos frente a una de las caracteristicas que normalmente convierte a un hecho en noticia: el conflicto.

9. Además, hay que contar con otro factor fundamental: la multiplicación de medios de comunicación. Esta dispersión mediática provoca la necesidad de conocer las técnicas de persuastón más adecuadas para cada uno de los soportes. 
uso que se haga del lenguaje en la redacción de estos escritos queda condicionado, pues, a esta finalidad.

Los comunicados de prensa que constituyen el corpus de estudio han sido dirigidos a la prensa de información general, y ello debe ser tenido en cuenta, pues el lenguaje será más específico cuando vayan dirigidas a la prensa técnica o especializada. Se trata de una selección de los emitidos desde el gabinete de prensa de la Fundación Tres Culturas del Mediterráneo (F3C), institución creada en 1998 por el Reino de Marruecos y la Junta de Andalucía con el objetivo, según figura en su página web (www.tresculturas.org), de "promover la paz, el diálogo y la tolerancia y facilitar de este modo las relaciones entre los distintos pueblos y culturas del Mediterráneo"10. Concretamente, se ha hecho una selección para analizar tres actos de perfiles distintos que tuvieron lugar en la sede de la F3C durante 2007: de carácter académico-formativo (curso impartido por Juan Goytisolo sobre "Guerra, periodismo y literatura", del 10 al 13 de abril), político-educativo (Foro de Alto Nivel de la OTAN, 8 de febrero) y, finalmente, exclusivamente cultural (exposición de acuarelas del pintor Mariano Bertuchi, del 1 al 18 de febrero). Estos tres actos fueron dados a conocer a los medios de comunicación a través de diversos comunicados de prensa redactados y enviados a las correspondientes redacciones con el objetivo de que alcanzaran la máxima difusión. Para llevar a cabo el análisis de las estrategias lingüísticas, en ocasiones se han contrastado estos comunicados con los textos a los que dieron origen en la prensa de información general.

\section{Las estrategias lingüísticas del comunicado de prensa}

Según se acaba de poner de manifiesto, las empresas no pueden prescindir del trabajo de la prensa para labrar su propia imagen. Aunque existen diversas vías de comunicación, las notas o comunicados de prensa ${ }^{11}$ constituyen una de las

10. A esta iniciativa se adhieren posteriormente el Centro Peres por la Paz, la Autoridad Nacional Palestina y otras personas e instituciones de Israel. Esta fundación cuenta, entre otras; con un importante número de actividades culturales, educativas y diplomáticas.

11. A pesar de que normalmente se entiende "comunicado de prensa" como un escrito informativo de carácter oficial propio de instituciones y organismos gubernamentales frente a la "nota de prensa", de índole comercial y, por lo tanto, más relacionada con el mundo empresarial, ambas expresiones se utilizarán indistintamente en este estudio. 
más rentables. En líneas generales, la redacción de los comunicados debe ser completa, clara, cortés, correcta y concisa. A continuación se tratará de poner de manifiesto las caracteristicas lingüisticas de los comunicados de prensa relacionándolas con cuatro de los objetivos que persiguen: (1) llamar la atención del periodista, (2) facilitarle la tarea de redacción, (3) presentarle los hechos como noticias y (4) publicitar o dar a conocer implícitamente la entidad. Los tres primeros guardan relación directa con el receptor inmediato al que se dirige un gabinete de prensa: el periodista. No obstante, cabe llamar la atención sobre la existencia de dos receptores: por un lado, el público final (lector, oyente o telespectador) y, por otro, el intermediario, es decir, el periodista, que actúa de filtro para decidir qué noticias se publican $^{12}$. Esta situación condicionará las estrategias lingüísticas empleadas, ya que el mensaje y su redacción deben concebirse, pues, de modo que sea aceptado por el periodista (noticiabilidad) ${ }^{13}$ y retransmitido con aceptación favorable al público final.

\subsection{Llamar la atención del periodista. Orden de palabra estratégicamente seleccionado}

Cada día llegan a la redacción de los medios de comunicación multitud de comunicados de prensa. La velocidad de los ritmos de trabajo hace que con frecuencia no todos reciban la misma atención e incluso muchos de ellos pasen desapercibidos o se desechen. Lograr captar la atención del periodista que recibe estos escritos para poder competir con otras entidades por el espacio informativo es el primer paso que hay que tener en cuenta en la redacción. De ahí la importancia de los titulares y entradillas ya que, una vez leídos, el periodista debe conocer la información para decidir el interés de la noticia. En ellos se da respuesta a los interrogantes clásicos (qué, quién, cuándo, cómo, dónde y por qué), haciendo hincapié en uno u otro en función de lo que interese destacar para convertir el hecho en noticia. El orden de palabras en estos casos juega un papel fundamental, ya que se trata de situar en primer lugar el elemento que contenga el mayor "enganche"

12. Podría hablarse, incluso, de un tercer receptor: las agencias de prensa, un medio de medios, a través de las cuales la información llega a los medios de comunicación al mismo tiempo. Uno de los objetivos que se persigue desde los gabinetes de comunicación es que los comunicados se incluyan en las agendas de estos organismos.

13. Es sabido que en to que se refiere al contenido, el criterio de "noticiabilidad" es variable: importancia de sus protagonistas, proximidad, trascendencia del hecho, novedad, curiosidad, dramatismo, etc. 
informativo ${ }^{14}$. Tradicionalmente, se ha considerado que el orden "neutro"15 del español obedece a la estructura (Sujeto)+Verbo+Complementos (SVC) ${ }^{16}$. En el corpus seleccionado se observa una tendencia a mantener esa estructura, siendo el primero de ellos el agente de la acción e informativamente elemento remático. En los comunicados de prensa es frecuente que se convierta en sujeto, situándola en el primer lugar de la cadena discursiva, la persona que interviene en el acto cuando esta es conocida por el público en general:

(5) Goytisolo imparte a partir de mañana en Tres Culturas el curso Guerra, periodismo y literatura.

En otros casos se destaca a la entidad como el actor que organiza, impulsa o planifica una actividad, de modo que se fomenta una imagen favorable de esta al constituirse en responsable último de un acto con trascendencia social:

(6) a. Tres Culturas reúne al Secretario General de la OTAN, el Ministro de Defensa Español y a alumnos universitarios en un diálogo sobre Afganistán.

b. La Fundación Tres Culturas presenta la exposición "Mariano Bertuchi: 50 años después", con la que rinde homenaje a este pintor precursor de las relaciones culturales entre España y Marruecos ${ }^{17}$.

14. Organizar un acto sea de la índole que sea requiere contar con una serie de entidades colaboradoras que también buscan aparecer nombradas en los medios. Muchas de estas entidades cuentan con sus propios gabinetes de comunicación pero no todas. De este modo, es har bitual que se citen a modo de cortesía en una posición destacada, sea en el titular, sea en el primer párrafo del texto: "Este encuentro, organizado por el CITpax en colaboración con la OTAN, el Ministerio de Defensa español y la Fundación Tres Culturas, pretende hacer un diagnóstico de la situación y recomendaciones genéricas sobre el modo de superar los problemas existentes".

15. Ese orden ha recibido muchos nombres: lógico, regular, normal, lineal, orden cero, neutro, objetivo... Sin embargo, todas estas expresiones parten del principio de que existe un orden establecido que se disloca.

16. En este punto habría que hacer una distinción entre oraciones transitivas e intransitivas. En las primeras el orden SVO es el propio de las lenguas románicas. Si el objeto ocupa la posición temática, es habitual en la lengua medieval quue el sujeto vaya detrás dell verbo mientras que en español moderno suele mantenerse en posición antepuesta. En este sentido se observa un ligero incremento del orden gramatical SV, al menos en las oraciones transitivas. Frente a esta situación, en las intransitivas la colocación del verbo y el sujeto es más variable, hecho que obedece a razones discursivas y semánticas. Así, por ejemplo, en aquellos verbos que indican un acontecimiento el sujeto suele ser el elemento remático, de ahí que vaya pospuesto. Al igual que sucede con estos "verbos de acontecer", el orden VS es muy habitual con sujeto no animado y verbos de fin, duración, suceso, presencia, etc.

17. Cuando se trata de un personaje poco conocido por el público general se especifica mediante aposición: "pintor precursor de las relaciones culturales entre España y Marruecos". 
Este orden tiende a alterarse en las noticias que originan estos comunicados en la prensa de información general, en las que constituye un recurso muy habitual nominalizar el titular suprimiendo las formas verbales, de modo que se logra no sólo acortarlo ${ }^{18}$ sino también evitar anclar la acción en unas coordenadas temporales determinadas:

(7) a. Literatura y guerra según Groytisolo (El País, 10/4/2007, pág. 56).

b. Supervivencia en Sarajevo según Goytisolo (La Razón, 11/4/2007).

c. Los colores de la luz de Marruecos, en una exposición de Bertuchi $(A b c$, 2/2/2007, pág. 70 ).

d. Bertuchi: un diario intimo del Marruecos novecentista (El Correo de Andalucia, 4/2/2007, pág. 41).

\section{2. Facilitar la tarea de redacción del periodista. Estructura de pirámide invertida}

Tener en cuenta no sólo la cantidad de comunicados que llegan a los periodistas a través del fax o del correo electrónico de las redacciones sino también la presión del tiempo en sus rutinas de trabajo conlleva a que los comunicados se redacten con el objetivo de simplificar la tarea de estos profesionales. Este hecho origina que se estructure a modo de noticia: título (convincente, breve, preciso y comprensible), encabezado o entradilla (esencial para incitar a la lectura) y cuerpo de texto (una idea por párrafo ordenada por importancia) ${ }^{19}$. Se suele incluir el nombre de la empresa desde el principio, preferentemente en el titular y la entradilla, con el objetivo de que, a pesar de que se recorte la información por cuestiones de espacio o interés, aparezca como elemento indispensable o sea lo último que se pueda descartar. La estructura sigue el orden de la pirámide invertida, es decir, los datos aparecen situados de mayor a menor importancia, colocando en primer término los más trascendentes y dejando para el final la información accesoria o menos relevante. En este punto entran en juego los intereses del gabinete: el primer término lo ocuparán de manera sutil, es decir, manteniendo un equilibrio con

18. Los programas informáticos de edición textual limitan notablemente el espacio asignado a un periodista para redactar una noticia, hecho que no ocurre en la elaboración de los comunicados de prensa, que cuentan con más libertad en este aspecto.

19. El nombre de la empresa debe aparecer en una posición destacada en alguna de estas tres partes (o en las tres), especialmente en el titular o entradilla. Es frecuente que aparezca varias veces. No obstante, los medios no suelen recogerlo en el titular sino en la entradilla o en el cuerpo de la noticia (también antetítulo). A veces tan sólo aparece en el pie de alguna foto tomada en la sede. Esto es frecuente que suceda con las entrevistas. 
la noticia en su totalidad, los datos de mayor interés para la empresa o institución que emite el comunicado.

\section{3. Presentar al periodista los hechos como noticias. Apariencia de objetividad}

La forma que envuelve el mensaje debe adoptar una serie de rasgos si quiere presentarse con objetividad ante los medios y, de este modo, ofrecer las características del hecho noticiable. Dos son los mecanismos lingüísticos más rentables para lograr este carácter neutro: la ausencia de adjetivos valorativos ${ }^{20}$ y el empleo de estructuras impersonales. Con respecto al primero de ellos, hay que decir que existe una preferencia por la adjetivación descriptiva y de relación o pertenencia ${ }^{21}$. Precisamente, una de las diferencias entre la nota de prensa y su publicación es que en esta última, especialmente cuando se trata de un género no estrictamente informativo (crónica, crítica, columna, etc.), sí aparece este tipo de adjetivo valorativo ${ }^{22}$ :

(8) a. Los dos políticos pasaron al fastuoso salón del antiguo pabellón de Marruecos, [...] $(A b c, 9 / 2 / 2007$, pág. 12).

b. El argumento se lo prestó el secretario general de la OTAN, Jaap Hoop Scheffer, con quien se entrevistó brevemente por la mañana en un lujoso hotel de la capital andaluza (El Pais, 9/2/2007, pág. 3).

c. Lidia Estévez, [...] fue quien puso ayer en apuros al mismo Jaap de Hoop Sche-

20. Cuando se emplea la adjetivación valorativa normalmente queda justificado el adjetivo con datos objetivos. Así, en el siguiente ejemplo, el adjetivo espectacular viene motivado por ei número de asistentes: "Julio Iglesias ofreció anoche un espectacular concierto que reunió a más de 25.000 personas en el estadio Santiago Bernabéu de Madrid".

21. Atendemos en este sentido a la clasificación de Rafael Lapesa (1975): (1) valorativos: adje:tivos que indican cualidades como bondad, dicha, grandeza, nobleza, intensidad, novedad, agrado y sus contrarios. Condiciones físicas y morales susceptibles de estimación, estados de ánimo, actitudes diversas, etc; (2) descriptivos: expresan una cualidad objetiva del sustantivo al que acompañan; (3) de relación o pertenencia: denotan situación, nacionalidad; materia, origen, clase, pertenencia, etc.; (4) cuasi determinativos: adjetivos y participios: cuya significación y funciones son análogas a las de los demostrativos, ordinales o cuantitativos y (5) anteposición formularia: estructuras fosilizadas (Sagradas escrituras, el Romano Pontífice, etc.).

22. La visión subjetiva del periodista es notable en los siguientes ejemplos: "Juan Goytiso-" lo [...] es sin duda una de las voces más independientes -y por ello de las más moles:tas-de la intelectualidad española" (entradilla a una entrevista, El Correo de Andalucia, 12/4/2007, pág. 41), "E1 seminario que imparte Juan Goytisolo en la Fundación Tres Culturas sobre guerra, periodismo y literatura, ha tenido el don de la oportunidad. Goytisolo, que hoy..." (Diario de Sevilla, 12/4/2007, pág. 14). 
ffer. Fue ella, como portavoz de otros estudiantes la que lanzó la pregunta más peliaguda: "¿Considera que los valores de la OTAN son coherentes consintiendo la existencia de Guantánamo?" (El Correo de Andalucía, 9/2/2007, pág. 4).

Con respecto al predominio de la impersonalidad, el profesional que trabaja en el gabinete de prensa sabe que no debe implicarse formalmente en la información que genera y transmite a los medios de comunicación. En este sentido, su papel se limita a ser intermediario entre la institución para la que trabaja y los medios, lo que conlleva que no aparezcan formas verbales o usos pronominales en primera persona. Es muy frecuente que se recurra a la tercera persona o a las construcciones con se:

(9) [...] Asimismo, se analizará el papel de meros espectadores que con frecuencia adoptan los ciudadanos ante las diversas crisis que baten el mundo.

Muchas veces la labor de los redactores que trabajan en los gabinetes de prensa termina cuando cubren el acto las agencias de prensa. Y ello es así porque son precisamente ellas las que venden la información a los medios. Eso explica que cuando asisten a un acto y elaboran una crónica de lo sucedido predomine el tono neutro y objetivo. Así, por ejemplo, en el caso del Foro de la OTAN, la nota de Europa Press se limita a resumir las intervenciones de las autoridades (ya se sabe que toda selección implica una manipulación). Este tono neutro disminuye en el caso de los periodistas de medios concretos que acuden a cubrir el acto, que se permiten algunas licencias estilísticas. Así, en la siguiente crónica se recurre para mantener la cohesión a las relaciones semánticas que contraen las palabras relacionadas con el mundo estudiantil (isotopía):

(10) Los universitarios andaluces aflaron bien sus lápices y tomaron ayer la palabra en la Fundación Tres Culturas, que les dio "carta blanca" para preguntar al secretario general de la OTAN y al ministro de Defensa. Y no defraudaron, los jóvenes querían saber y preguntaron con puntería (Correo de Andalucía, 9/2/2007, pág. 4).

o se juega con el doble sentido de una frase activando ambas interpretaciones (anfibología). Así, en el siguiente titular se actualizan dos posibles sentidos: (1) la falta de paraguas del Secretario General al que el director de la Fundación tuvo que resguardar bajo el de un periodista y (2) la falta de implicación en la pregunta formulada por los estudiantes sobre la posición de la OTAN ante los presos de Guantánamo:

(11) La OTAN no se moja $(A b c, 11 / 2 / 2007$, pág. 21). 


\section{4. Publicitar la entidad/vender el mensaje}

Según se puso de manifiesto anteriormente, el objetivo fundamental de los comunicados de prensa es lograr captar espacio informativo en la prensa para ir creando una imagen favorable de la entidad. Para lograrlo, es habitual que en el texto aparezcan datos relacionados con ella. El mensaje institucional ${ }^{23}$, es decir, el que define a la institución (creación, objetivos, características, líneas de actuación, etc.) aparece en determinadas ocasiones, especialmente en aquellos actos de perfil medio-alto o de carácter internacional, ya que la prensa extranjera o nacional requiere normalmente más información en este sentido. El mensaje institucional suele aparecer en estos casos en el primer párrafo del cuerpo del comunicado. En el caso del Foro de Alto Nivel de la OTAN, además de al principio,

(12) La Fundación Tres Culturas, institución que desde su nacimiento en 1998 a instancias del Gobierno andaluz y el Reino de Marruecos, ha tenido como objetivo promover el diálogo, la paz y el respeto entre pueblos y culturas del Mediterráneo, acoge el próximo jueves 8 de febrero un Foro de Alto Nivel que, bajo el título Afganistány el impacto de la adaptación de la OTAN a los nuevos desafios, reunirá a estudiantes de distintas universidades andaluzas y de la Escuela Diplomática con los responsables directos del diseño y la puesta en práctica de la estrategia de acción de la Alianza Atlántica.

el mensaje institucional aparece al final del texto a modo de cierre circular del comunicado:

(13) Este encuentro tendrá lugar en la sede de la Fundación Tres Culturas, situada en el Pabellón Hassan II - antiguo pabellón de Marruecos de la Expo del 92 de Sevilla-en la Isla de La Cartuja. Desde hace más de siete años este lugar se ha convertido en un espacio donde se trabaja desde Andalucía para construir una región euromediterránea más comprensiva y más cercana, más tolerante con el otro, donde Tres Culturas promueve, con una extensa programación de eventos abiertos al público, el diálogo interreligioso, social, económico, cultural y político ${ }^{24}$.

23. Para Álvarez/Caballero (1997: 182): “Los gabinetes deben realizar comunicados de prensa de todos aquelkos acontecimientos que consideren de interés general. Hay que tener muy en cuenta que estas informaciones, aunque van dirigidas a los periodistas, tienen como objetivo último el ser publicadas. Consecuentemente, además de aportar los datos concretos del acontecimiento, obra o proyecto que queramos vender, debemos incluir el eje comunicacional de nuetra entidad, de forma que toda la sociedad vaya asimilando la política de nues": tra organización".

24. Este comunicado fue enviado a los medios el 5 de febrero, aunque se siguieron enviando notas recordatorias. La agencia EFE lo recoge el mismo día pero elimina el mensaje ins- 
Una herramienta de alta rentabilidad para lograr captar espacio informativo es hacer atractiva al periodista alguna de las personas que intervienen en el acto. De este modo, es frecuente que en el cuerpo de la nota se destaquen algunos datos biográficos (pactados previamente) con el fin de que se concierte una entrevista $\mathrm{y}$, de este modo, la institución (aunque sea como mero marco) aparezca citada en los medios. Es lo que ocurre con el comunicado enviado sobre el curso de Goytisolo y la exposición de Bertuchi, que recogen un pequeño curriculum de ambos en el cuerpo de texto.

\section{Conclusión}

Es sabido que todo texto se inserta en una tradición discursiva que le confiere unas características lingüísticas y estructurales determinadas siempre en función de la finalidad que se persiga. Son conocidos los rasgos que en este sentido presentan determinados géneros periodísticos tales como las noticias, los artículos, las entrevistas, etc. pero en este ámbito se ha desatendido un tipo de texto que cada vez cobra más importancia como instrumento de comunicación en el ámbito empresarial: el comunicado de prensa. Tras este breve análisis del corpus seleccionado, puede deducirse que formalmente se configuran con las características propias de los géneros informativos. Así, es frecuente que se mantenga el orden sujeto + verbo + complementos en los titulares y entradillas. No obstante, esta disposición puede alterarse en la prensa de información general, que muestra mayor variedad en este sentido, siendo habitual que se suprima el verbo. Por su parte, la estructura textual de los comunicados de prensa y de las noticias que originan no suelen variar, ya que los primeros se redactan (con el objetivo de simplificar la tarea del periodista) a modo de pirámide invertida, reservando el primer lugar para aquellos datos de mayor interés para la prensa. Esta disposición intencionada para lograr promocionar la entidad se trata de contrarrestar con la apariencia de objetividad que proporciona la ausencia de adjetivación valorativa y el predominio de estructuras impersonales. No hay nada, pues, de inocente o improvisado en la redacción de este tipo de textos. Sus características lingüísticas y su estructura pretenden, de manera sutil, hacer un hueco a la empresa en el panorama informativo de la actualidad inmediata.

titucional. El resto de medios se hace eco el día antes del encuentro (Diario de Sevilla, 7/2/2007, pág. S.3; El Correo de Andalucia, 7/2/2007, pág. 12) o incluso el mismo (Diario de Sevilla, 8/2/2007, pág. 19). 


\section{Referencias bibliográficas}

Álvarez, Tomás/Caballero, Mercedes (1997): Vendedores de imagen. Los retos de los nuevos gabinetes de comunicación. Barcelona: Paidós Ibérica.

Bustos Tovar, José Jesús (1997): "Organización textual y oralidad", en: Briz Gómez, Antonio et al. (eds.): Sobre l'oral i l'ecrit. Almería: Universidad de Almería, 7-24.

Koch, Peter/OESTERREICHER, Wulf (1990): Gesprochene Sprache in der Romania: Französisch, Italienisch, Spanisch. Tübingen: Max Niemeyer.

LAPESA, Rafael (1975): "La colocación del calificativo atributivo en español", en: Homenaje a la memoria de Don Antonio Rodríguez-Moñino 1910-1970. Madrid: Castalia, 329-345.

López Serena, Araceli (2002): Reseña de: Peter Koch y Wolf Oesterreicher (1990): Gesprochene Sprache in der Romania: Franzöisch, Italienisch, Spanisch, Tübingen, Max Niemeyer, en: Lexis 26, 1, 255-271.

Méndez García de Paredes, Elena. (2003): "Lo hablado en lo escrito: la entrevista periodística", en: Oralia 6, 169-214.

Oesterreicher, Wulf. (1997): "Pragmática del discurso oral", en: Berg, Walter Bruno/ Schäffauer, Markus Klaus (eds.): Oralidad y argentinidad. Tübingen: Gunter Narr Verlag, 86-97. 